\title{
Microwave Assisted Extraction of Defatted Roselle (Hibiscus sabdariffa L.) Seed at Subcritical Conditions with Statistical Analysis
}

\author{
N. I. Yusoff and C. P. Leo \\ School of Chemical Engineering, Universiti Sains Malaysia, Engineering Campus, 14300 Nibong Tebal, Pulau Pinang, Malaysia \\ Correspondence should be addressed to C. P. Leo; chcpleo@usm.my
}

Received 7 July 2016; Revised 30 August 2016; Accepted 31 August 2016; Published 10 January 2017

Academic Editor: Amy Simonne

Copyright (C) 2017 N. I. Yusoff and C. P. Leo. This is an open access article distributed under the Creative Commons Attribution License, which permits unrestricted use, distribution, and reproduction in any medium, provided the original work is properly cited.

\begin{abstract}
Roselle seeds are the waste product of roselle processing, but they are now labeled as a polyphenol source with great herbal quality. In this work, polyphenols were extracted using ethanol-water $(70 \%(\mathrm{v} / \mathrm{v}))$ in a closed vessel under microwave irradiation. The main objective was to determine the optimal parameters statistically. The influence of extraction time (4-10 min), microwave power $(100-300 \mathrm{~W})$, and solvent/solid ratio $(25-100 \mathrm{~mL} / \mathrm{g})$ was studied. The total phenolic and flavonoids content were determined using Folin-Ciocalteu and aluminum chloride methods, respectively. Without temperature control, the subcritical conditions could occur and the highest flavonoid content $(14.4251 \mathrm{mg} \mathrm{QE} / \mathrm{g})$ was achieved at $158^{\circ} \mathrm{C}$ and 16.4 bar. Although the optimum MAE conditions (10 min, $300 \mathrm{~W}$, and $97.7178 \mathrm{~mL} / \mathrm{g}$ ) resulted in the highest yield (65.0367\%) and phenolic content (18.2244 mg GAE/g), low flavonoids content (6.4524 mg QE/g) was unexpectedly obtained due to degradation at $163^{\circ} \mathrm{C}$.
\end{abstract}

\section{Introduction}

Roselle (Hibiscus sabdariffa L.) is widely cultivated in tropical and subtropical regions as a traditional remedy. Besides being used as the coloring agent in the food industry, the roselle calyces (sepals of a flower) are commercialized in the form of beverages, juices, jam, dried fruit, and syrup products due to their bioactive content. Roselle calyces have been long recognized as a source of antioxidants, but roselle seed extract was scientifically proven to possess the highest antioxidant content among the extracts of other parts of a roselle plant, including calyces, stems, and leaves [1]. However, the total phenolic content (TPC) of roselle seed extract varied greatly as reported in several works [2-4]. The variation could be related to the difference in the solvent selection or the method used. The improvement in extraction practice and technology aptitude actually helps to increase the phenolic content extracted from roselle seed. Using subcritical water at the optimum conditions, the phenolic content of roselle seed extract could be increased up to 12 times $(56.72 \mathrm{mg} \mathrm{GAE} / \mathrm{g}$ extract) [4].
Since the subcritical water extraction involves a high temperature range of 100 to $374^{\circ} \mathrm{C}$ and high pressure (50100 bar), other advanced methods of extraction with low energy consumption should be considered for roselle seed. Ultrasound-assisted extraction (UAE) not only reduced the extraction time from few hours to less than an hour but also increased the phenolic content of defatted hemp, flax, canola [5], and grape seed extract [6] compared to the control extract. UAE was reported to be less suitable for the grape seed defatted by UAE, resulting in a drop in TPC. A long application of ultrasound could cause the degradation of bioactive compounds [6]. Also, the industrial scale-up of UAE was rated as very challenging [7]. Microwave assisted extraction (MAE) of polyphenols from other seeds has also been recently studied. Microwave is the electromagnetic wave with a wavelength ranging from $1 \mathrm{~m}$ to $1 \mathrm{~mm}$ and frequency falling between $300 \mathrm{MHz}$ and $300 \mathrm{GHz}$. Microwave enables the uniform heating of seed and solvent efficiently, reducing the solvent consumption and extraction in comparison to conventional methods of extraction. The highest TPC in the grape seed extract, $73.15 \mathrm{mg}$ GAE/g DW, was achieved using 
$50 \mathrm{wt} \%$ ethanolic solution and microwave power of $373.15 \mathrm{~W}$ within $1 \mathrm{~min}$ [2]. This optimum phenolic content is slightly lower than the TPC of the grape seed extract $(86.51 \mathrm{mg}$ GAE/g DW) which was conventionally extracted in $30 \mathrm{~min}$ without microwave radiation. The degradation of phenolic compounds could occur at the fast elevated temperature caused by microwave irradiation. Most of the phenolic compounds degrade following the first-order kinetics model in the temperature of $100-250^{\circ} \mathrm{C}$ and disappear at $250^{\circ} \mathrm{C}$ [8]. However, the microwave assisted aqueous two-phase extraction (MAATPE) was reported to assist the extraction of more phenolic compounds from grape seed (82.7 mgGAE/g) [9] compared to Soxhlet extraction (36.8 mgGAE/g). Teh et al. [10] also reported that MAE of defatted flax seed cake under the optimum conditions $(5 \mathrm{~min}, 644 \mathrm{~W}$, and $6 \mathrm{~mL}$ solvent to $1 \mathrm{~g}$ of seed) could result in extract with TPC of $1128.53 \mathrm{mg} \mathrm{GAE} / 100 \mathrm{~g}$ (fw) which is slightly higher than the TPC of extract prepared using pulsed electric field technology. The similar conditions were found to be optimum in the extraction of canola seed cake (2292.52 mg GAE/100 $\mathrm{g} \mathrm{fw}$ ) and hemp seed cake (1330.54 mg GAE/100 g fw) as well $[11,12]$. MAE of polyphenols from seeds could still be a success if the degradation of bioactive compounds can be minimized. The degradation of polyphenols in extract could be avoided by proper control of temperature during microwave irradiation [13]. Most of the studies on MAE of seed, however, did not report on the effects of temperature. The household microwave oven was used in these studies without temperature monitoring or control.

In this work, a temperature sensor was used to monitor the temperature changes in MAE while studying the effects of duration, microwave power and solid to solvent ratio. It is important to understand the phenolic degradation under microwave irradiation as such information has not been published to the best of our knowledge. A closed vessel was also used to study the possibility of MAE at higher pressure in order to achieve effective extraction of polyphenols from roselle seeds under subcritical conditions. Furthermore, the extraction was optimized via design of experiment (DOE).

\section{Materials and Methods}

2.1. Materials. The seeds of Hibiscus sabdariffa L. (UKMR2 species) were collected from the plants grown at Malacca, Malaysia. Methanol $(\mathrm{MeOH})$, ethanol (EtOH), and sodium carbonate $\left(\mathrm{Na}_{2} \mathrm{CO}_{3}\right)$ were purchased from Merck (Darmstadt, Germany). Folin-Ciocalteu's phenol reagent, quercetin, and gallic acid were purchased from Sigma-Aldrich (St. Louis, USA). Aluminum chloride $\left(\mathrm{AlCl}_{3}\right)$ was purchased from Fluka (USA). All chemicals used were of analytical grade and sourced from commercial suppliers.

2.2. Sample Preparation. Roselle seeds were dried in a forcedoven (Memmert UFB500) at $40^{\circ} \mathrm{C}$ to constant weight and then grounded using a chilled mortar. The seed powder was passed through a standard $355 \mu \mathrm{m}$ sieve and only the fraction with particle size lower than $355 \mu \mathrm{m}$ was collected. Samples were then defatted following Ismail and Yee [14] method with modifications of defatting times before being stored in a freezer at $-20^{\circ} \mathrm{C}$ in airtight bags until further use.

2.3. MAE of Roselle Seed. A closed-system of MAE reported in our previous work [13] was operated in a microwave oven CEM-Mars 6 (CEM Corporation, USA). The roselle seed powder with a variation of solvent/solid ratio was added to the extraction vessel with $50 \mathrm{~mL}$ of ethanol-water (70\%-30\%) mixture. The mixture was stirred using a magnetic stirrer to homogenize the sample as well as to achieve a uniform temperature distribution in the system during microwave irradiation. According to the experimental design, extraction was performed at a varied extraction time ( $\mathrm{min})$, microwave power $(\mathrm{W})$, and solvent/solid ratio $(\mathrm{mL} / \mathrm{g})$ with three replicates. After MAE treatment, the extract was then separated from solids by vacuum filtration and stored at $-20^{\circ} \mathrm{C}$ for further analysis. All extracts were then evaluated for their yield, phenolic, and flavonoids content.

2.4. Determination of Roselle Seed Extract Quality. The roselle seed extract $(10 \mathrm{~mL})$ was placed in a round bottom flask and was frozen at $-80^{\circ} \mathrm{C}$ before being freeze-dried under high vacuum for $24 \mathrm{~h}$. The weight of the dried extract was determined and the yield was then calculated based on the actual amount of seed used in the particular experiment.

TPC in roselle seeds extract was determined using the Folin-Ciocalteu method reported by Singleton et al. [15] and was expressed as mg gallic acid equivalent (GAE) per gram of dry extract (mg GAE/g). First, $250 \mu \mathrm{L}$ of sample extract was mixed with $250 \mu \mathrm{L}$ of Folin-Ciocalteu's phenol reagent (diluted in water $1: 1$ ), $500 \mu \mathrm{L}$ of $20 \% \mathrm{Na}_{2} \mathrm{CO}_{3}$, and $4 \mathrm{~mL}$ of distilled water. The mixture was mixed thoroughly and incubated in the dark at room temperature for $20 \mathrm{~min}$ before being centrifuged for another $10 \mathrm{~min}$ at $3000 \mathrm{rpm}$. The mixture was analyzed with UV-Vis Spectrophotometer (Cary 60 UV-Vis, Agilent Technologies, USA) at $760 \mathrm{~nm}$. The TPC was determined by plotting against the gallic acid calibration curve from 0 to $250 \mathrm{mg} \mathrm{GAE} / \mathrm{L}(y=0.0075 x+0.0315$, $\left.r^{2}=0.9995\right)$.

The flavonoids content was estimated using the modified aluminum chloride colorimetric method [16]. The flavonoid content was expressed as mg quercetin equivalent per gram of dry extract (mg QE/g). The sample extract $(500 \mu \mathrm{L})$ was mixed with $250 \mu \mathrm{L}$ of $5 \% \mathrm{AlCl}_{3}$ and $4.25 \mathrm{~mL}$ methanol. After $30 \mathrm{~min}$ of incubation, the absorbance was read at $425 \mathrm{~nm}$. The total flavonoid content was determined by plotting against the quercetin calibration curve from 0 to $100 \mu \mathrm{g} / \mathrm{mL}(y=$ $\left.0.0059 x-0.0063, r^{2}=0.9975\right)$.

2.5. Experimental Design. The response surface methodology (RSM) was applied to evaluate the effect of the extraction parameters and to identify the optimal conditions for three defined responses in the MAE of roselle seed. Extraction time $(A)$, microwave power $(B)$, and solvent/solid ratio $(C)$ were independent variables that were optimized for the three responses which are extraction yield, TPC, and total flavonoid content. 
TABLE 1: Experimental design for the extraction process obtained from central composite design (CCD) and corresponding responses.

\begin{tabular}{|c|c|c|c|c|c|c|c|c|c|}
\hline \multirow{3}{*}{ Run } & \multicolumn{3}{|c|}{ Independent variable } & \multicolumn{3}{|c|}{ Responses } & \multirow{3}{*}{$\begin{array}{c}T_{\max } \\
{ }^{\circ} \mathrm{C}\end{array}$} & \multirow{3}{*}{$\begin{array}{l}P_{\max } \\
\text { Bar }\end{array}$} & \multirow{3}{*}{ Vapor fraction } \\
\hline & $A$ & $B$ & C & $R_{1}$ & $R_{2}$ & $R_{3}$ & & & \\
\hline & $\min$ & $\mathrm{W}$ & $\mathrm{mL} / \mathrm{g}$ & $\%$ & $\mathrm{mg} \mathrm{GAE} / \mathrm{g}$ & $\mathrm{mg} \mathrm{QE/g}$ & & & \\
\hline 1 & 7 & 200 & 62.5 & 26.8490 & 13.5000 & 3.8585 & 125 & 6.5 & 0 \\
\hline 2 & 7 & 200 & 62.5 & 35.5122 & 15.5500 & 6.8826 & 132 & 8.1 & 0 \\
\hline 3 & 10 & 100 & 25 & 21.2813 & 11.1167 & 2.7157 & 101 & 2.7 & 0 \\
\hline 4 & 7 & 300 & 62.5 & 43.3767 & 15.8025 & 7.9784 & 139 & 9.8 & 0 \\
\hline 5 & 4 & 300 & 25 & 28.2500 & 12.0353 & 3.4522 & 127 & 6.6 & 0 \\
\hline 6 & 7 & 200 & 62.5 & 30.7205 & 15.0506 & 5.9225 & 130 & 7.7 & 0 \\
\hline 7 & 7 & 200 & 62.5 & 33.6198 & 13.4445 & 8.4663 & 130 & 7.3 & 0 \\
\hline 8 & 10 & 300 & 100 & 63.5000 & 17.9055 & 14.4251 & 158 & 16.4 & 0 \\
\hline 9 & 7 & 200 & 62.5 & 26.1458 & 13.8562 & 4.6594 & 129 & 7.3 & 0 \\
\hline 10 & 10 & 200 & 62.5 & 34.0104 & 15.6493 & 9.5308 & 138 & 9.7 & 0 \\
\hline 11 & 4 & 100 & 100 & 27.5000 & 10.4017 & 2.4896 & 88 & 1.2 & 1 \\
\hline 12 & 4 & 300 & 100 & 31.2500 & 14.0391 & 6.4539 & 131 & 7.2 & 0 \\
\hline 13 & 7 & 200 & 25 & 29.0105 & 13.0349 & 5.8925 & 135 & 8.8 & 0 \\
\hline 14 & 10 & 300 & 25 & 59.0521 & 14.2493 & 4.5561 & 151 & 14.1 & 0 \\
\hline 15 & 4 & 100 & 25 & 17.0000 & 9.6644 & 1.6985 & 81 & 0.7 & 1 \\
\hline 16 & 7 & 100 & 62.5 & 21.4323 & 13.1577 & 3.4329 & 107 & 3.6 & 0 \\
\hline 17 & 4 & 200 & 62.5 & 27.6649 & 12.9401 & 4.2035 & 119 & 5.3 & 0 \\
\hline 18 & 7 & 200 & 100 & 32.6667 & 13.1936 & 6.2006 & 122 & 6.0 & 0 \\
\hline 19 & 10 & 100 & 100 & 26.8333 & 12.3017 & 3.6894 & 106 & 3.1 & 0 \\
\hline 20 & 7 & 200 & 62.5 & 28.3594 & 15.5853 & 5.7097 & 129 & 6.3 & 0 \\
\hline
\end{tabular}

Design-Expert ${ }^{\circledR}$ (Version 10, Stat-Ease, Inc., Minneapolis, USA) package was used to establish a mathematical model and obtain the optimum conditions for maximum recovery of the three responses. In the present study, a central composite design (CCD) was developed and used to examine the effects of independent variables within the defined ranges. The independent variables used in this work were the extraction time ( $A$ from 4 to $10 \mathrm{~min}$ ), microwave power ( $B$ from 100 to $300 \mathrm{~W}$ ), and solvent/solid ratio (C from 25 to $100 \mathrm{~mL} / \mathrm{g}$ ) resulting in 20 randomized experiments, including six replicates as the centre points. Each individual extraction experiment was conducted in triplicate, as opposed to only the final analysis. Table 1 showed the experimental design obtained from the CCD. The ranges for all variables were selected based on the single-factor experimental results during preliminary study.

The experimental data were then fitted to a quadratic polynomial model which was shown in the following general equation:

$$
Y=\alpha_{0}+\sum_{i=1}^{k} \alpha_{i} X_{i}+\sum_{i=1}^{k} \alpha_{i i} X^{2}+\sum_{i>j}^{k} \alpha_{i j} X_{i} X_{j}
$$

where $Y$ represents the predicted response, $X_{i}$ and $X_{j}$ represent the actual independent variables, $\alpha_{0}$ is a constant coefficient that fixed the response at the central point of the experiment, and $\alpha_{i}, \alpha_{i i}$, and $\alpha_{i j}$ are the regression coefficients of the linear, quadratic, and interaction terms, respectively. The adequacy of the model was predicted through the ANOVA analysis. The terms in the models that were not significant $(P>0.05)$ were removed from the equations and the experimental data were refitted to obtain a reduced model. Finally, the additional experiments were conducted using the optimal conditions predicted by the RSM, and the experimental value was then compared to the predicted value obtained from the optimized model to verify the validity of the models.

2.6. Flash Calculation for Subcritical Analysis. The subcritical extraction could be achieved if the solvent was heated between the atmospheric boiling point and the critical point without vaporization. The flash temperature and pressure of ethanol-water mixture without the formation of vapor were first determined based on UNIFAC (UNIQUAC FunctionalGroup Activity Coefficients) method using Aspen Plus V8.0. The vapor fraction of the ethanol-water mixture was also calculated using the maximum temperature and pressure recorded in each experimental run.

\section{Results and Discussion}

3.1. Model Analysis. The experimental results of MAE conducted according to the CCD matrix are presented in Table 1. The correlation between the MAE factors (extraction time, microwave power, and solid/solvent ratio) and the three measured responses (extraction yield, TPC, and total flavonoid content) fitted the second-order polynomial equation. Based on the maximum temperature and pressure recorded in each experimental run, the vapor fraction was calculated. All runs except Runs numbers 11 and 15 achieved subcritical 
TABLE 2: The analysis of variance (ANOVA) for the fitted models.

\begin{tabular}{|c|c|c|c|c|c|c|}
\hline \multirow[b]{2}{*}{ Source } & \multicolumn{2}{|c|}{$R_{1}$} & \multicolumn{2}{|c|}{$R_{2}$} & \multicolumn{2}{|c|}{$R_{3}$} \\
\hline & $F$-value & $\begin{array}{c}P \text { value } \\
\text { Prob }>F\end{array}$ & $F$-value & $\begin{array}{c}P \text { value } \\
\text { Prob }>F\end{array}$ & $F$-value & $\begin{array}{c}P \text { value } \\
\text { Prob }>F\end{array}$ \\
\hline Model & 42.99 & $<0.0001$ & 23.05 & $<0.0001$ & 9.64 & 0.0005 \\
\hline$A$ & 40.05 & $<0.0001$ & 21 & 0.0004 & 9.06 & 0.0088 \\
\hline$B$ & 93.2 & $<0.0001$ & 43.07 & $<0.0001$ & 17.11 & 0.0009 \\
\hline C & 5.54 & 0.0326 & 8.54 & 0.0105 & 7.32 & 0.0163 \\
\hline$A B$ & 33.17 & $<0.0001$ & & & & \\
\hline \multicolumn{7}{|l|}{$A C$} \\
\hline$B C$ & & & & & 5.06 & 0.04 \\
\hline \multicolumn{7}{|l|}{$A^{2}$} \\
\hline \multicolumn{7}{|l|}{$B^{2}$} \\
\hline$C^{2}$ & & & 19.61 & 0.0005 & & \\
\hline Lack-of-fit & 0.9 & 0.5862 & 0.53 & 0.8162 & 1.22 & 0.4373 \\
\hline$R^{2}$ & 0.9198 & & 0.8601 & & 0.7199 & \\
\hline CV\% & 11.33 & & 6.15 & & 31.12 & \\
\hline Adequate precision & 23.334 & & 17.794 & & 12.462 & \\
\hline
\end{tabular}

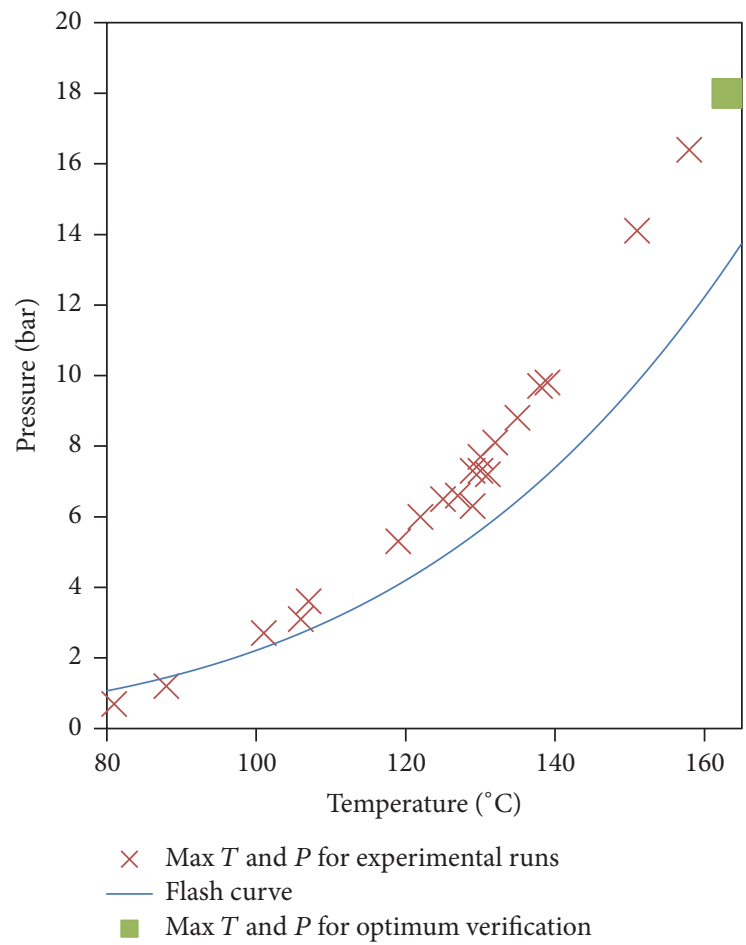

FIGURE 1: The comparison of maximum temperature and pressure achieved in all experimental and verification runs to the flash curve of ethanol-water mixture without vapor fraction.

conditions without vapor formation as shown in Figure 1. Analysis of variance (ANOVA) was further performed to investigate the adequacy of the suggested models and to identify the significant factors in the models (Table 2).

The coefficients of determination $\left(R^{2}\right)$ values for all responses obtained by statistical analyses indicated a good correlation between the experimental results and predicted values by the model (Table 2). The insignificant lack-of-fit value $(P>0.05)$ indicated the validity of models to describe the functional relationship between the experimental and the response variable accurately [17]. As presented in Table 2, the factors with the significant effects on the extraction yield $(P<$ 0.05 ) were the linear terms of $A, B$, and $C$ and the interaction terms of $A B$. Meanwhile, $A C$ and $B C$ were not significant $(P>0.05)$ because they played a negligible role in the models. The following equations presented the relationship between the responses and the tested variables after the backward reduction:

$$
\begin{aligned}
& R_{1}=32.20+7.30 A+11.14 B+2.72 C+7.43 A B, \\
& R_{2}=14.45+1.21 A+1.74 B+0.77 C-1.66 C^{2}, \\
& R_{3}=5.61+1.66 A+2.28 B+1.49 C+1.39 B C,
\end{aligned}
$$

where $R_{1}$ (extraction yield), $R_{2}$ (TPC), and $R_{3}$ (total flavonoid content) are the responses and the independent variables are $A$ (extraction time), $B$ (microwave power), and $C$ (solvent/solid ratio).

3.2. The Influence of the Extraction Parameters on the Extraction Yield. The extraction yield varied from 17 to $63.5 \%$ under the tested MAE conditions. All the linear terms ( $A$, $B$, and $C$ ) had a significant effect on the extraction yield, but the extraction time as well as the microwave power showed more significant effect than the ratio of solvent to solid. Moreover, the interaction parameter which is $A B$ influenced the extraction yield significantly. The order of factors influencing the response value of the extraction yield by observing linear and quadratic coefficients was as follows: microwave power $>$ extraction time $>$ solvent/solid ratio. According to (2), the positive coefficients of $A, B$, and $C$ variables indicated the increment in response value by the positive changes of these factors. Run 8 (extraction time: 


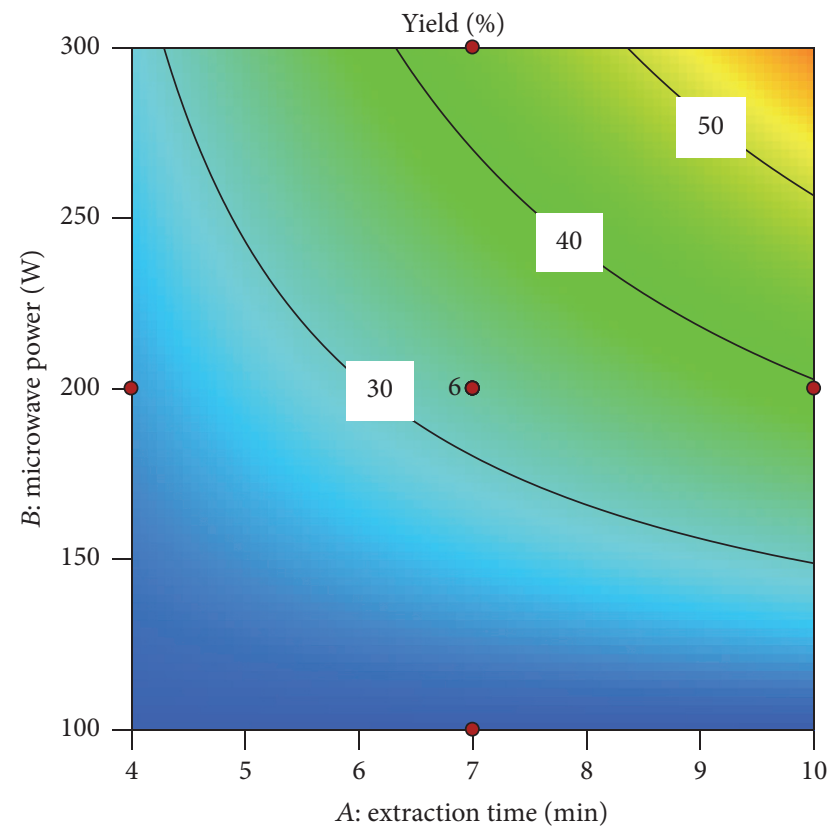

Design-expert software
Factor coding: actual yield (\%)
- Design points
П3.5
17

$X 1=A$ : extraction time

$X 2=B$ : microwave power

Actual factor

C: solvent ratio $=62.5$

FIGURE 2: Response surface plot of the interaction between time $(A)$ and power $(B)$ on the extraction yield of roselle seed.

$10 \mathrm{~min}$, microwave power: $300 \mathrm{~W}$, and solvent/solid ratio: $100 \mathrm{~mL} / \mathrm{g}$ ) achieved the highest yield and the value was 3 times higher than the yield reported by Susanti et al. [3] who used Soxhlet extraction as summarized in Table 3. Based on the temperature profile recorded, it was found that yield increased with increasing temperature. A higher temperature allows better transfer of active components into the solvent. It was found to result in the decreasing surface tension and viscosity of the solvent at a higher temperature in the subcritical state [18].

The contour plots, a graphical representation of a response surface, were drawn to study the influences of the independent variables and the corresponding effect on the response. Jain et al. [19] mentioned that it is easy to understand both the main and interaction effects of the independent variables on the response using the graph. Figure 2 shows the combined effect of extraction time and microwave power on the yield with fixed level of solvent/solid ratio. The extraction yield of roselle seed increased significantly by elevating the extraction time and microwave power instead of the ratio of solvent to solid (Figure 3 ). This finding was in line with the theory that the yield increases when the extraction time is extended at constant power before reaching the degradation stage. Sinha et al. [20] who worked on MAE of Bixa orellana (annato) seed also reported that the extraction yield increased proportionally with the extraction time as well. Meanwhile, the experimental results in Figure 2

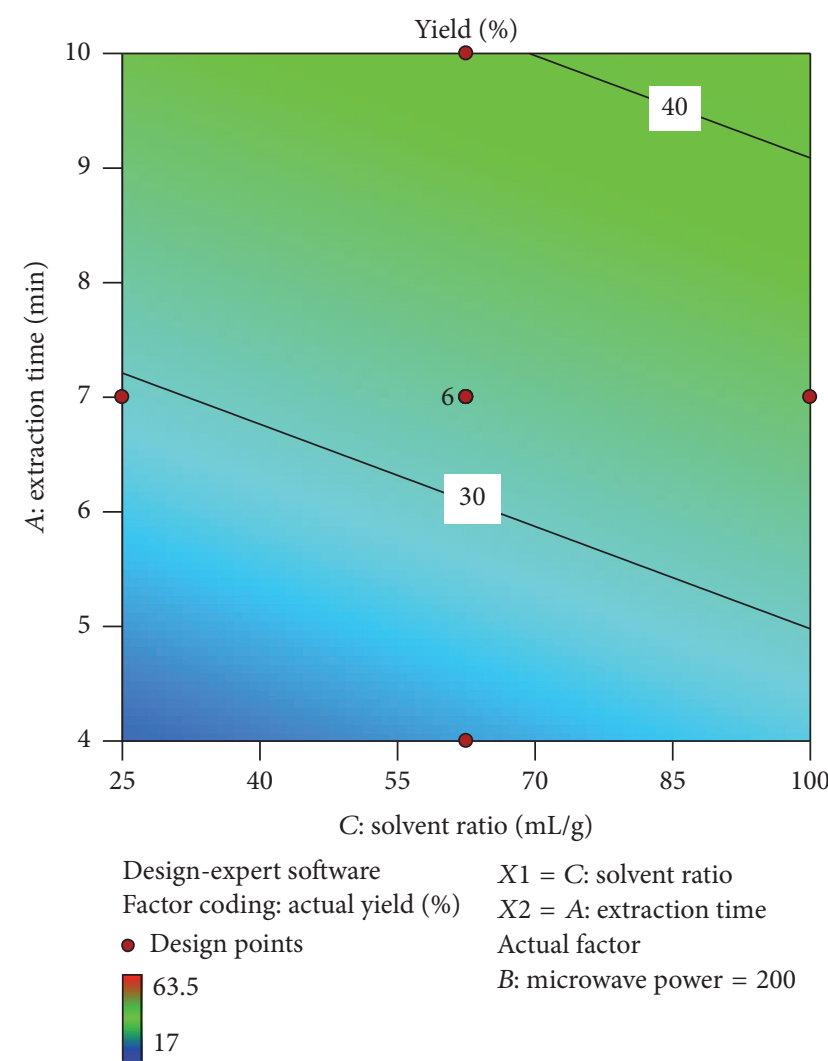

FIGURE 3: Response surface plot of the interaction between solvent/solid ratio $(C)$ and time $(A)$ on the extraction yield of roselle seed.

followed the predicted theory by $\mathrm{Hu}$ et al. [21] that the increasing of microwave power improves the extract yield. Microwave radiation heats and increases the pressure on the cell walls until the plant tissue rupture [22]. Hence, the interaction between solvent and roselle seed in the extraction process was improved for achieving high yield.

\subsection{The Influence of the Extraction Parameters on the Total} Polyphenol Content. Under the tested MAE conditions, the TPC in roselle seed extract fell in the range of 9.6644 to $17.9055 \mathrm{mg}$ GAE per g of dry extract. Table 2 shows the model with satisfactory fitting (Prob $>F(0.05)$, correlation coefficient $\left.R^{2}=0.8601\right)$. All the values of Prob $>F$ for the factors of $A, B, C$, and $C^{2}$ were lower than 0.05 , indicating that the polyphenol content was significantly influenced by these factors. The positive coefficients of $A, B$, and $C$ variables further revealed that their positive changes can promote the extraction of phenolic compounds. Meanwhile, the negative quadratic coefficient of $C^{2}$ indicated that the opening of equation parabola was downward. The increment of TPC was limited; even the ratio of solvent/solid ratio was further increased as shown in Runs 11, 12, 18, and 19 listed in Table 1.

The response surface for TPC by varying extraction time and microwave power is shown in Figure 4. The simultaneous growth in the extraction duration and the microwave power amplified TPC from 9.66 to $17.91 \mathrm{mg}$ GAE/g dry extract. The 
TABLE 3: Comparison of microwave assisted extraction (MAE) and conventional extractions from previous studies.

\begin{tabular}{lccccrr}
\hline Solvent & $\begin{array}{c}\text { Extraction } \\
\text { yield (\%) }\end{array}$ & $\begin{array}{c}\text { Total phenolic } \\
\text { content } \\
\text { mg GAE/g extract }\end{array}$ & $\begin{array}{c}\text { Total flavonoid } \\
\text { content }\end{array}$ & Extraction method & Duration (min) & Reference \\
\hline $70 \%(v / v)$ ethanol & - & 18.3000 & - & Maceration & 120 & Ismail and Yee [14] \\
Distilled water & - & 2.9700 & - & Maceration & 120 & Mohd-Esa et al. [1] \\
$80 \%(v / v)$ methanol & - & 12.8700 & - & Maceration & 120 & Mohd-Esa et al. [1] \\
Ethanol & 20.1 & 12.9600 & $\begin{array}{c}3.1190 \mathrm{mg} \mathrm{CE} / \mathrm{g} \\
\text { extract }\end{array}$ & Soxhlet & 1440 & Susanti et al. [3] \\
$70 \%(\mathrm{v} / \mathrm{v})$ ethanol & 63.5 & 17.9055 & $14.4251 \mathrm{mg} \mathrm{QE} / \mathrm{g}$ & MAE & 10 & This work \\
\hline
\end{tabular}

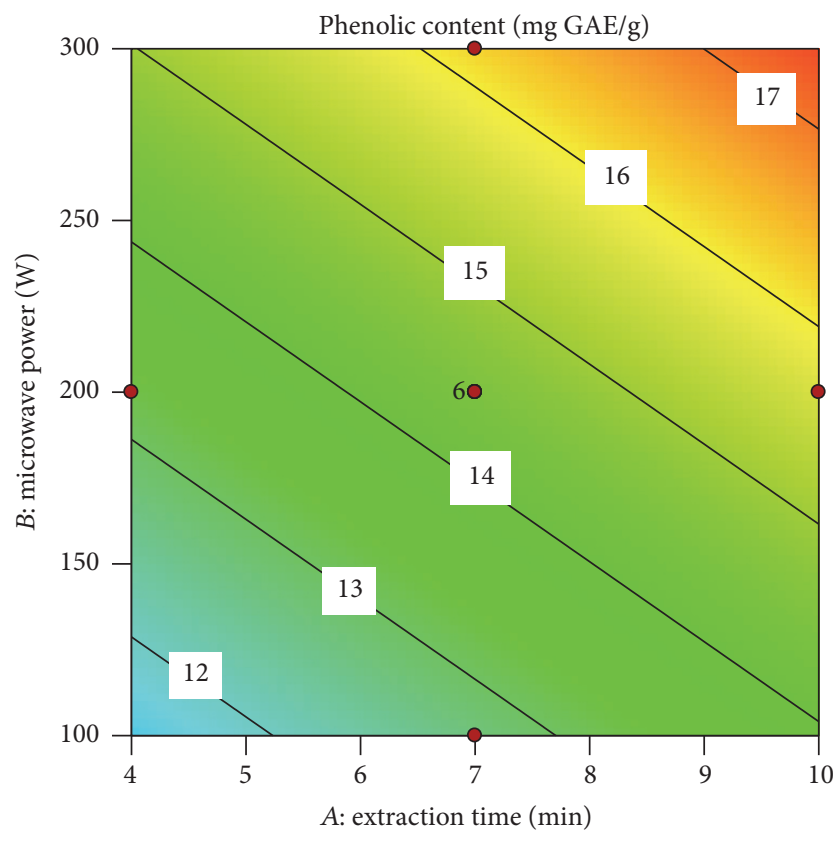

$\begin{array}{ll}\text { Design-expert software } & X 1=A \text { : extraction time } \\ \text { Factor coding: actual } & X 2=B \text { : microwave power } \\ \text { phenolic content }(\mathrm{mg} \mathrm{GAE} / \mathrm{g}) & \begin{array}{l}\text { Actual factor } \\ \text { C: solvent ratio }=62.5 \\ \text { Design points }\end{array} \\ \square \begin{array}{l}17.9055 \\ 9.6644\end{array}\end{array}$

FIGURE 4: Response surface plot of the interaction between time $(A)$ and power $(B)$ on the total phenolic content of roselle seed.

reduction of TPC was not observed in this response surface which is bounded by the appropriate operating range. Beyond the boundary, particularly microwave power more than $300 \mathrm{~W}$, a great drop of the extract quality in terms of color and odor was noticed during preliminary study as shown in supplementary document (Figure S1, in Supplementary Material available online at https://doi.org/10.1155/2017/5232458). The similar observation was reported in other studies on MAE [23, 24]. TPC of the extract started to decrease at higher microwave power $(400$ to $500 \mathrm{~W})$ in these reports. Figure 4 also shows that the amount of polyphenols in roselle seed extracts increased when extraction time was increased up to $10 \mathrm{~min}$. However, the TPC in extracts is expected

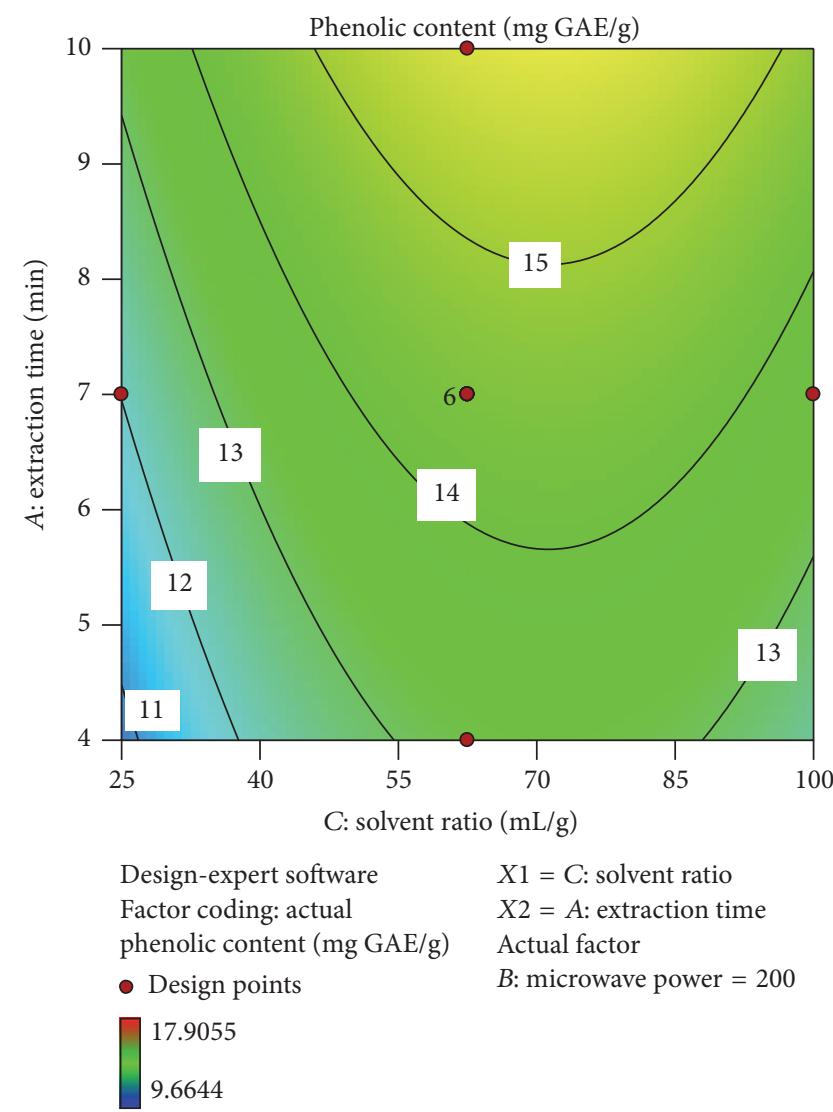

FIgURE 5: Response surface plot of the interaction between solvent/solid ratio $(C)$ and time $(A)$ on the total phenolic content of roselle seed.

to decrease with longer extraction duration and exposure to the microwave irradiation. Madhujith and Shahidi [25] mentioned that prolonging extraction time may induce the oxidation of phenolic compounds in the plant material. Moreover, Wang et al. [26] confirmed that phenolic content decreases under the long exposure of microwave and they deduced that the decrement should be related to the high temperature instead of the high pressure.

The response surface in Figure 5 shows the interaction between solvent/solid ratio and extraction time and their effects on TPC in extract. In general, a higher amount of solvent is needed to promote the recovery of TPC in extract. 
It is not favorable because more solvent is required to be removed. Therefore, it is important to ensure the solvent/solid ratio is as small as possible but still enough for the recovery [27]. To the best of our knowledge, previous attempts to extract polyphenols from roselle seed using MAE method have not been reported. Other studies involved different extraction techniques and a lower amount of polyphenols was obtained; even the extraction time was much longer than our work. Compared to other extraction methods, MAE offers short extraction time as summarized in Table 3. Interestingly, all the summarized studies for roselle seed extraction differ dramatically in terms of the time required. Mohd-Esa et al. [1] used water and methanol (80\%) as solvent in the extraction of polyphenols from roselle seed. They obtained low yield of $2.97 \pm 0.17 \mathrm{mg} \mathrm{GAE} / \mathrm{g}$ and $4.87 \pm 0.14 \mathrm{mg} \mathrm{GAE} / \mathrm{g}$, respectively. Ismail and Yee [14] extracted polyphenols from roselle seed using ethanol-water (70\%-30\%) solution via maceration. The mixture of solvent was stirred for $2 \mathrm{hr}$ and then left for another $24 \mathrm{hr}$. The amount of TPC obtained was $18.3 \mathrm{mg}$ GAE/g which is slightly higher than our results $(17.9055 \mathrm{mg}$ GAE/g) after $24 \mathrm{hr}$.

3.4. The Influence of the Extraction Parameters on the Total Flavonoid Content. The total flavonoid content of roselle seed extracts was evaluated by aluminum chloride colorimetric method. This class of compounds normally occurred as flavonol and flavanol type in simple or polymerized form which can be extracted from roselle flower and leaves [28] while ergosterol can be extracted from seed [29]. The amounts of total flavonoid content in the extracts were varied from 1.6985 to $14.4251 \mathrm{mg}$ QE per g of dry extract. It was influenced by all three linear terms $(A, B$, and $C)$ and an interaction term $(B C)$, but the most influential factor was microwave power. Comparing (3) and (4), the total polyphenol and total flavonoid content were affected by the similar influential factors. The results in this study also showed that the favorable conditions for achieving high content of flavonoid and the conditions required for high polyphenol content are alike. For example, the response surface plots (Figure 6) showed the positive effects of the interaction between solvent ration $(C)$ and time $(A)$ on the total flavonoid content. As reported by Ramić et al. [30], such results could be expected because flavonoids represent a subgroup of polyphenols.

In this study, it was found that microwave power plays an important role in influencing all the corresponding responses since it contributes to the heating rate in MAE. Table 1 shows that a very high temperature $\left(>127^{\circ} \mathrm{C}\right)$ was recorded whenever high microwave power of $300 \mathrm{~W}$ was applied. The heating was enhanced as more electromagnetic energy is transferred towards the extraction process. As shown in Figure 7, the flavonoid content increased by elevating the microwave power. The hydrogen bonding strength in water will decrease as the temperature increases at subcritical state [31]. It makes the solvent become less polar and in return increases the solubility of some organic compounds. In addition, the heat and mass transfer during the MAE occurred in the same direction from inside to outside of the

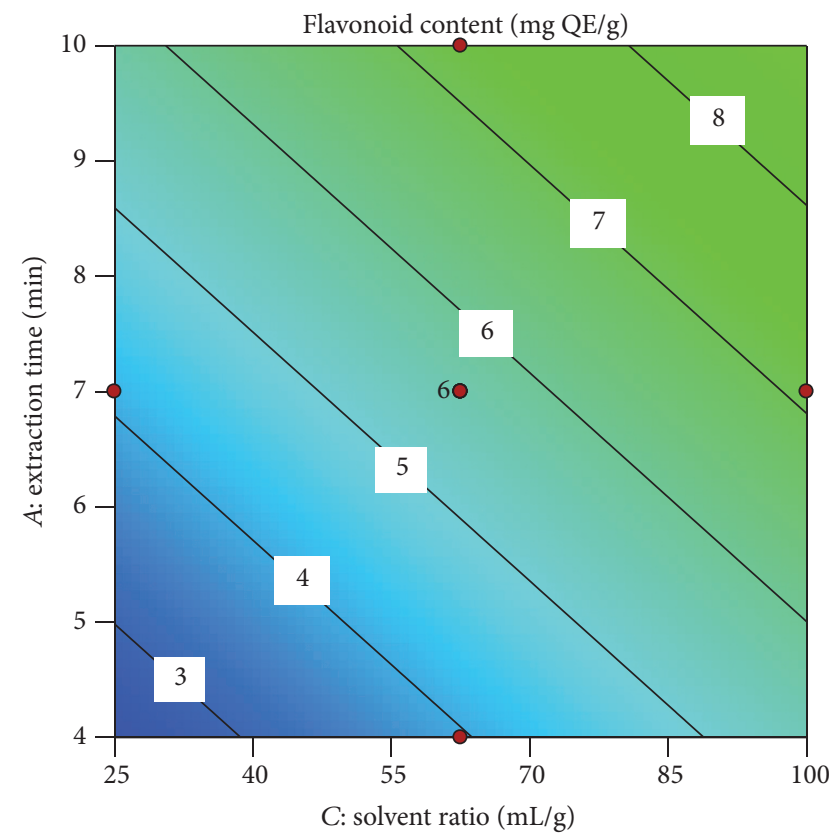

$$
\begin{aligned}
& \text { Design-expert software } \\
& \text { Factor coding: actual } \\
& \text { flavonoid content (mg QE/g) } \\
& \text { - Design points } \\
& 14.4251 \\
& 1.6985
\end{aligned}
$$

$$
\begin{aligned}
& X 1=C \text { : solvent ratio } \\
& X 2=A \text { : extraction time } \\
& \text { Actual factor } \\
& B: \text { microwave power }=200
\end{aligned}
$$

FIGURE 6: Response surface plot of the interaction between solvent/solid ratio $(C)$ and time $(A)$ on the total flavonoid content of roselle seed.

samples. It stimulates the solubilisation of solutes faster than the conventional methods which involve the heat transfer from outside to the inside of samples [32].

3.5. Verification of the Predictive Model. The optimum conditions obtained from the desirability function approach were tested to evaluate the reliability of the model equations. The optimized variables were as follows: extraction time of $10 \mathrm{~min}$; microwave power of $300 \mathrm{~W}$; and solventto-solid ratio of $97.7178 \mathrm{~mL} / \mathrm{g}$ (Table 4). The predicted value for extraction yield was $60.6212 \%$ (95\% prediction interval (PI) $51.21-70.03$ ). The TPC of $16.6702 \mathrm{mg}$ GAE/g (95\% PI 14.58-18.76) and the total flavonoid content of $12.2640 \mathrm{mg}$ QE/g (95\% PI 7.78-16.74) were predicted as well. The actual results for the extraction yield and TPC obtained from the experimental data were consistent with the predictive values. These responses fitted within 95\% PI and the achieved yield and TPC are $65.0367 \%$ and $18.2244 \mathrm{mg} \mathrm{GAE} / \mathrm{g}$, respectively, showing that the models were reliable. However, the total flavonoid content $(6.4524 \mathrm{mg} \mathrm{QE} / \mathrm{g}$ ) was lower than 95\% PI value which indicated that the model for this response was less reliable. Checking the temperature profile, subcritical extraction with high temperature and pressure $\left(163^{\circ} \mathrm{C} ; 18 \mathrm{bar}\right)$ was actually achieved as shown in Figure 1 . The degradation of flavonoid compounds could happen beyond $158^{\circ} \mathrm{C}$. In the 
TABLE 4: The results of experimental verification.

\begin{tabular}{|c|c|c|c|c|c|c|}
\hline & $\begin{array}{l}\text { Extraction time } \\
\qquad(\mathrm{min})\end{array}$ & $\begin{array}{l}\text { Microwave power } \\
\text { (W) }\end{array}$ & $\begin{array}{l}\text { Solvent/solid ratio } \\
\qquad(\mathrm{mL} / \mathrm{g})\end{array}$ & $\begin{array}{c}\text { Extraction yield } \\
\qquad(\%)\end{array}$ & $\begin{array}{l}\text { Total phenolic } \\
\text { content } \\
\text { (mg GAE/g) }\end{array}$ & $\begin{array}{c}\text { Total flavonoid } \\
\text { content } \\
(\mathrm{mg} \mathrm{QE} / \mathrm{g})\end{array}$ \\
\hline Predicted & 10 & 300 & 97.7178 & 60.6212 & 16.6702 & 12.2640 \\
\hline Actual $^{\mathrm{a}}$ & 10 & 300 & 97.7135 & 65.0367 & 18.2244 & 6.4524 \\
\hline
\end{tabular}

${ }^{\mathrm{a}}$ The maximum temperature and pressure recorded are $163^{\circ} \mathrm{C}$ and $18 \mathrm{bar}$, respectively.

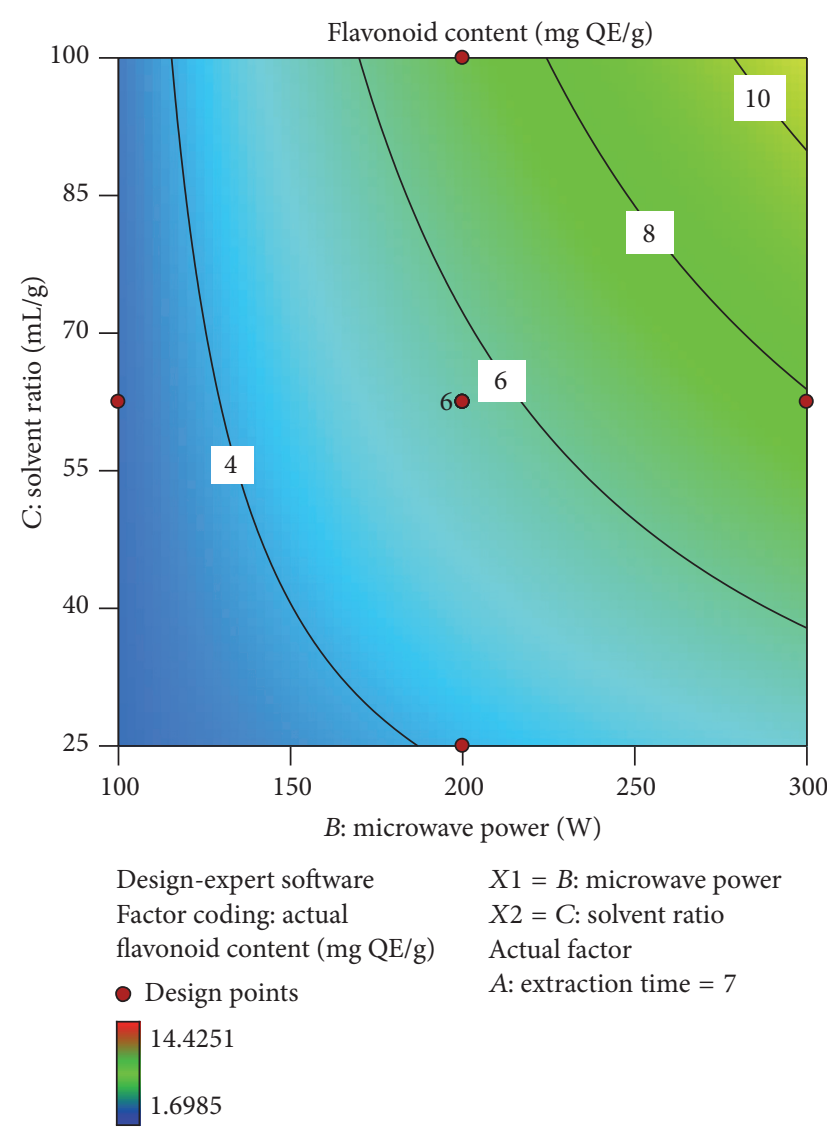

Figure 7: Response surface plot of the interaction between microwave power $(B)$ and solvent/solid ratio $(C)$ on the total flavonoid content of roselle seed.

closed vessel, the increasing solvent temperature in the range of $60-120^{\circ} \mathrm{C}$ usually enhances the efficiency of MAE [33]. The extraction performed between $130^{\circ} \mathrm{C}$ and $150^{\circ} \mathrm{C}$ could cause a sharp degradation of some thermolabile compounds but increase the concentration of others. The degradation degree at $150^{\circ} \mathrm{C}$ depends on the compound polarity due to microwave-selective heating. The flavonoid compounds are thermolabile and should be extracted with temperature being controlled [34].

\section{Conclusions}

The subcritical extraction of defatted roselle seed was successfully conducted using a closed vessel under microwave irradiation. In addition, the polynomial model applied in this study represented the good approximation of yield and TPC of roselle seed extract during MAE due to adequate ANOVA and descriptive statistical parameters $\left(R^{2}\right.$ and $\left.C V\right)$. The optimum total flavonoid content was not achieved as it is more thermally sensitive and a proper temperature control is required to prevent degradation. However, the statistical analysis is still helpful to understand the effects of extraction time, microwave power, and solvent-to-solid ratio on extract quality preliminary. The extract yield and total phenolic as well as flavonoid content were most affected by microwave irradiation. Besides proper temperature control, microwave power irradiation should be limited in the MAE of roselle seed in the future works.

\section{Additional Points}

Practical Application. The extract quality of roselle seed can be maximized by controlling the operating parameters in microwave assisted extraction (MAE). However, the flavonoid content could be degraded at high temperature. This study demonstrated that MAE in a closed vessel could be practically used to conduct subcritical extraction as well. Nevertheless, the subcritical extraction under microwave irradiation was limited by the vessel materials and design. It is important to prevent accidental overpressurization to ensure process safety.

\section{Competing Interests}

The authors declare that there is no conflict of interests regarding the publication of this paper. The received funding did not lead to any conflict of interests regarding the manuscript publication.

\section{Acknowledgments}

The authors would like to acknowledge the Ministry of Higher Education of Malaysia for providing financial support via LRGS (304/PJKIMIA/6050296/U124) and MyMaster (Ms. Nurul Izyatulikma binti Yusoff). The authors would also like to thank Universiti Sains Malaysia for the equipment provided through Membrane Science and Technology Cluster (1001/PSF/8610013).

\section{References}

[1] N. Mohd-Esa, F. S. Hern, A. Ismail, and C. L. Yee, "Antioxidant activity in different parts of roselle (Hibiscus sabdariffa L.) 
extracts and potential exploitation of the seeds," Food Chemistry, vol. 122, no. 4, pp. 1055-1060, 2010.

[2] S. Medouni-Adrar, L. Boulekbache-Makhlouf, Y. Cadot et al., "Optimization of the recovery of phenolic compounds from Algerian grape by-products," Industrial Crops and Products, vol. 77, pp. 123-132, 2015.

[3] D. Susanti, M. Osman, and N. N. Draman, "Natural antioxidant contents in the seeds of four Roselle Malaysian varieties and a Kenaf: a comparison," Journal of Herbs, Spices and Medicinal Plants, vol. 18, no. 3, pp. 240-245, 2012.

[4] N. Y. Tran-Thi, M. Yuliana, N. S. Kasim, N. T. Hong Le, D.Y. Lee, and Y.-H. Ju, "Subcritical water extraction of phenolicrich product from defatted roselle seed," Journal of Chemical Engineering of Japan, vol. 45, no. 11, pp. 911-916, 2012.

[5] S.-S. Teh and E. J. Birch, "Effect of ultrasonic treatment on the polyphenol content and antioxidant capacity of extract from defatted hemp, flax and canola seed cakes," Ultrasonics Sonochemistry, vol. 21, no. 1, pp. 346-353, 2014.

[6] C. Da Porto, E. Porretto, and D. Decorti, "Comparison of ultrasound-assisted extraction with conventional extraction methods of oil and polyphenols from grape (Vitis vinifera L.) seeds," Ultrasonics Sonochemistry, vol. 20, no. 4, pp. 1076-1080, 2013.

[7] M. Vinatoru, "An overview of the ultrasonically assisted extraction of bioactive principles from herbs," Ultrasonics Sonochemistry, vol. 8, no. 3, pp. 303-313, 2001.

[8] P. Khuwijitjaru, J. Plernjit, B. Suaylam, S. Samuhaseneetoo, R. Pongsawatmanit, and S. Adachi, "Degradation kinetics of some phenolic compounds in subcritical water and radical scavenging activity of their degradation products," Canadian Journal of Chemical Engineering, vol. 92, no. 5, pp. 810-815, 2014.

[9] Y.-Y. Dang, H. Zhang, and Z.-L. Xiu, "Microwave-assisted aqueous two-phase extraction of phenolics from grape (Vitis vinifera) seed," Journal of Chemical Technology and Biotechnology, vol. 89, no. 10, pp. 1576-1581, 2014.

[10] S.-S. Teh, B. E. Niven, A. E.-D. A. Bekhit, A. Carne, and J. Birch, "Optimization of polyphenol extraction and antioxidant activities of extracts from defatted flax seed cake (Linum usitatissimum L.) using microwave-assisted and pulsed electric field (PEF) technologies with response surface methodology," Food Science and Biotechnology, vol. 24, no. 5, pp. 1649-1659, 2015.

[11] S.-S. Teh, B. E. Niven, A. E.-D. A. Bekhit, A. Carne, and E. J. Birch, "The use of microwave and pulsed electric field as a pretreatment step in ultrasonic extraction of polyphenols from defatted hemp seed cake (Cannabis sativa) using response surface methodology," Food and Bioprocess Technology, vol. 7, no. 11, pp. 3064-3076, 2014.

[12] S.-S. Teh, B. E. Niven, A. E.-D. A. Bekhit, A. Carne, and E. J. Birch, "Microwave and pulsed electric field assisted extractions of polyphenols from defatted canola seed cake," International Journal of Food Science and Technology, vol. 50, no. 5, pp. 11091115, 2015.

[13] N. Hamzah and C. P. Leo, "Microwave-assisted extraction of Trigona propolis: the effects of processing parameters," International Journal of Food Engineering, vol. 11, no. 6, pp. 861870, 2015.

[14] A. Ismail and C. L. Yee, "Antioxidative effects of extracts of cocoa shell, roselle seeds and a combination of both extracts on the susceptibility of cooked beef to lipid oxidation," Journal of Food Technology, vol. 4, no. 1, pp. 10-15, 2006.
[15] V. L. Singleton, R. Orthofer, and R. M. Lamuela-Raventós, "Analysis of total phenols and other oxidation substrates and antioxidants by means of folin-ciocalteu reagent," in Methods in Enzymology, vol. 299, pp. 152-178, Academic Press, New York, NY, USA, 1999.

[16] C.-C. Chang, M.-H. Yang, H.-M. Wen, and J.-C. Chern, "Estimation of total flavonoid content in propolis by two complementary colometric methods," Journal of Food and Drug Analysis, vol. 10, no. 3, pp. 178-182, 2002.

[17] K.-W. Kong, A. R. Ismail, S.-T. Tan, K. M. Nagendra Prasad, and A. Ismail, "Response surface optimisation for the extraction of phenolics and flavonoids from a pink guava puree industrial byproduct," International Journal of Food Science \& Technology, vol. 45, no. 8, pp. 1739-1745, 2010.

[18] B. Tangkhavanich, Y. Oishi, T. Kobayashi, and S. Adachi, "Properties of rice stem extracts obtained by subcritical water/ethanol treatment," Food Science and Technology Research, vol. 19, no. 4, pp. 547-552, 2013.

[19] M. Jain, V. K. Garg, and K. Kadirvelu, "Investigation of $\mathrm{Cr}(\mathrm{VI})$ adsorption onto chemically treated Helianthus annuus: optimization using response surface methodology," Bioresource Technology, vol. 102, no. 2, pp. 600-605, 2011.

[20] K. Sinha, S. Chowdhury, P. D. Saha, and S. Datta, "Modeling of microwave-assisted extraction of natural dye from seeds of Bixa orellana (Annatto) using response surface methodology (RSM) and artificial neural network (ANN)," Industrial Crops and Products, vol. 41, no. 1, pp. 165-171, 2013.

[21] Z. Hu, M. Cai, and H.-H. Liang, "Desirability function approach for the optimization of microwave-assisted extraction of saikosaponins from Radix Bupleuri," Separation and Purification Technology, vol. 61, no. 3, pp. 266-275, 2008.

[22] M. Dhobi, V. Mandal, and S. Hemalatha, "Optimization of microwave assisted extraction of bioactive flavonolignansilybinin," Journal of Chemical Metrology, vol. 3, pp. 13-23, 2009.

[23] B. Nayak, F. Dahmoune, K. Moussi et al., "Comparison of microwave, ultrasound and accelerated-assisted solvent extraction for recovery of polyphenols from Citrus sinensis peels," Food Chemistry, vol. 187, pp. 507-516, 2015.

[24] X.-H. Yuan, L.-N. Fu, C.-B. Gu, Y.-D. Zhang, and Y.-J. Fu, "Microwave-assisted extraction and antioxidant activity of vaccarin from the seeds of Vaccaria segetalis," Separation and Purification Technology, vol. 133, pp. 91-98, 2014.

[25] T. Madhujith and F. Shahidi, "Optimization of the extraction of antioxidative constituents of six barley cultivars and their antioxidant properties," Journal of Agricultural and Food Chemistry, vol. 54, no. 21, pp. 8048-8057, 2006.

[26] Y. Wang, J. You, Y. Yu et al., "Analysis of ginsenosides in Panax ginseng in high pressure microwave-assisted extraction," Food Chemistry, vol. 110, no. 1, pp. 161-167, 2008.

[27] M. Ravber, Ž. Knez, and M. Škerget, "Simultaneous extraction of oil- and water-soluble phase from sunflower seeds with subcritical water," Food Chemistry, vol. 166, pp. 316-323, 2015.

[28] I. Da-Costa-Rocha, B. Bonnlaender, H. Sievers, I. Pischel, and M. Heinrich, "Hibiscus sabdariffa L.-a phytochemical and pharmacological review," Food Chemistry, vol. 165, pp. 424-443, 2014.

[29] R. B. Salama and S. A. Ibrahim, "Ergosterol in Hibiscus sabdariffa seed oil," Planta Medica, vol. 36, no. 7, pp. 221-222, 1979.

[30] M. Ramić, S. Vidović, Z. Zeković, J. Vladić, A. Cvejin, and B. Pavlić, "Modeling and optimization of ultrasoundassisted extraction of polyphenolic compounds from Aronia 
melanocarpa by-products from filter-tea factory," Ultrasonics Sonochemistry, vol. 23, pp. 360-368, 2015.

[31] K. S. Duba, A. A. Casazza, H. B. Mohamed, P. Perego, and L. Fiori, "Extraction of polyphenols from grape skins and defatted grape seeds using subcritical water: experiments and modeling," Food and Bioproducts Processing, vol. 94, pp. 29-38, 2015.

[32] A. N. Mustapa, Á. Martin, R. B. Mato, and M. J. Cocero, "Extraction of phytocompounds from the medicinal plant Clinacanthus nutans Lindau by microwave-assisted extraction and supercritical carbon dioxide extraction," Industrial Crops and Products, vol. 74, pp. 83-94, 2015.

[33] E. Destandau, T. Michel, and C. Elfakir, "Microwave assisted extraction," in Natural Product Extraction: Principles and Applications, M. A. Rostagno and J. M. Prado, Eds., pp. 113-156, Royal Society of Chemistry, Cambridge, UK, 2013.

[34] E. M. Silva, H. Rogez, and Y. Larondelle, "Optimization of extraction of phenolics from Inga edulis leaves using response surface methodology," Separation and Purification Technology, vol. 55, no. 3, pp. 381-387, 2007. 

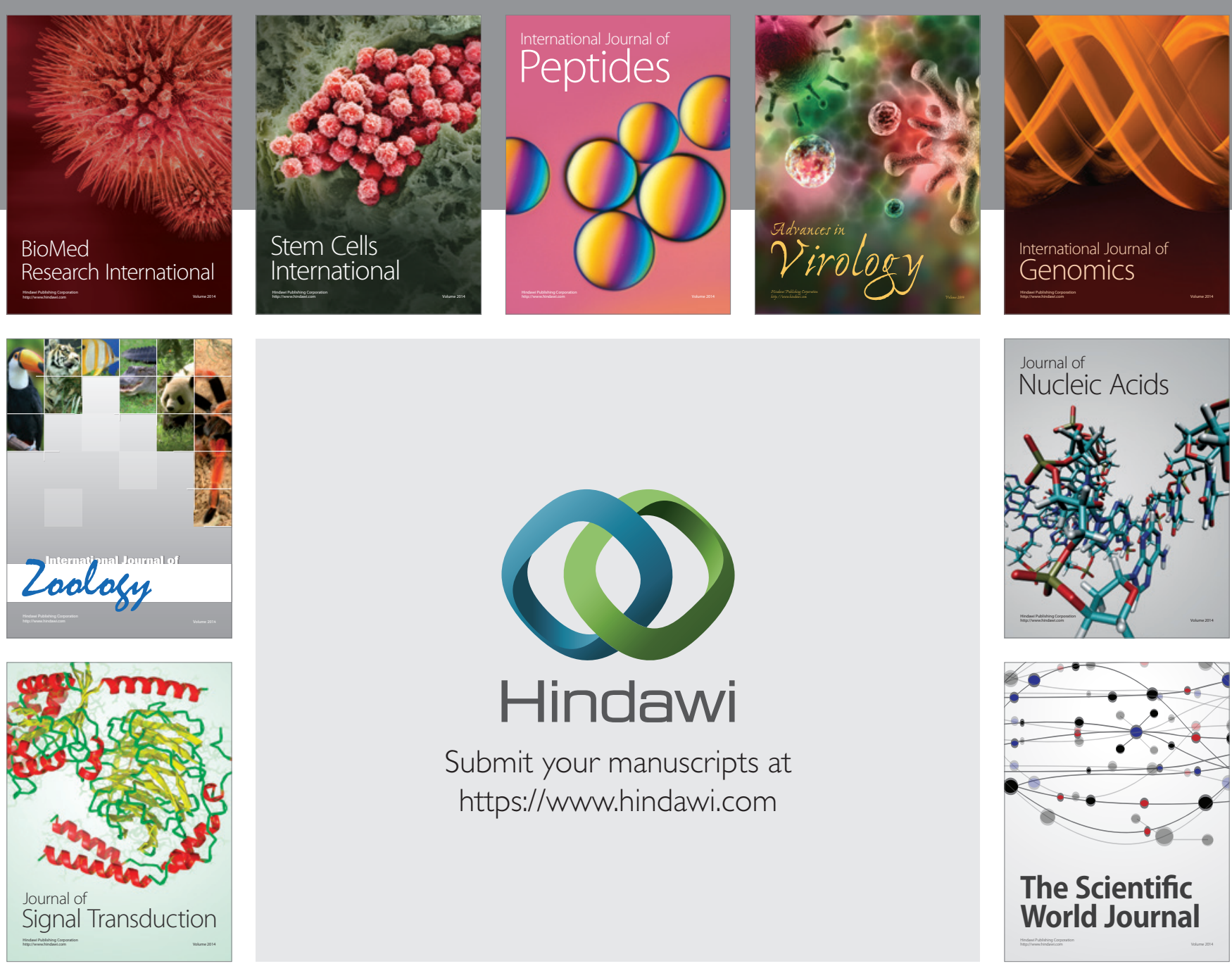

Submit your manuscripts at

https://www.hindawi.com
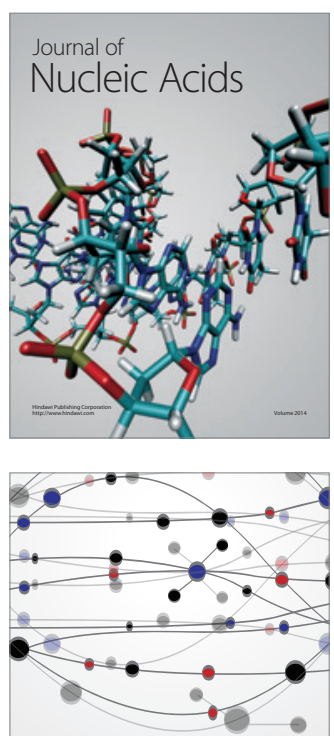

The Scientific World Journal
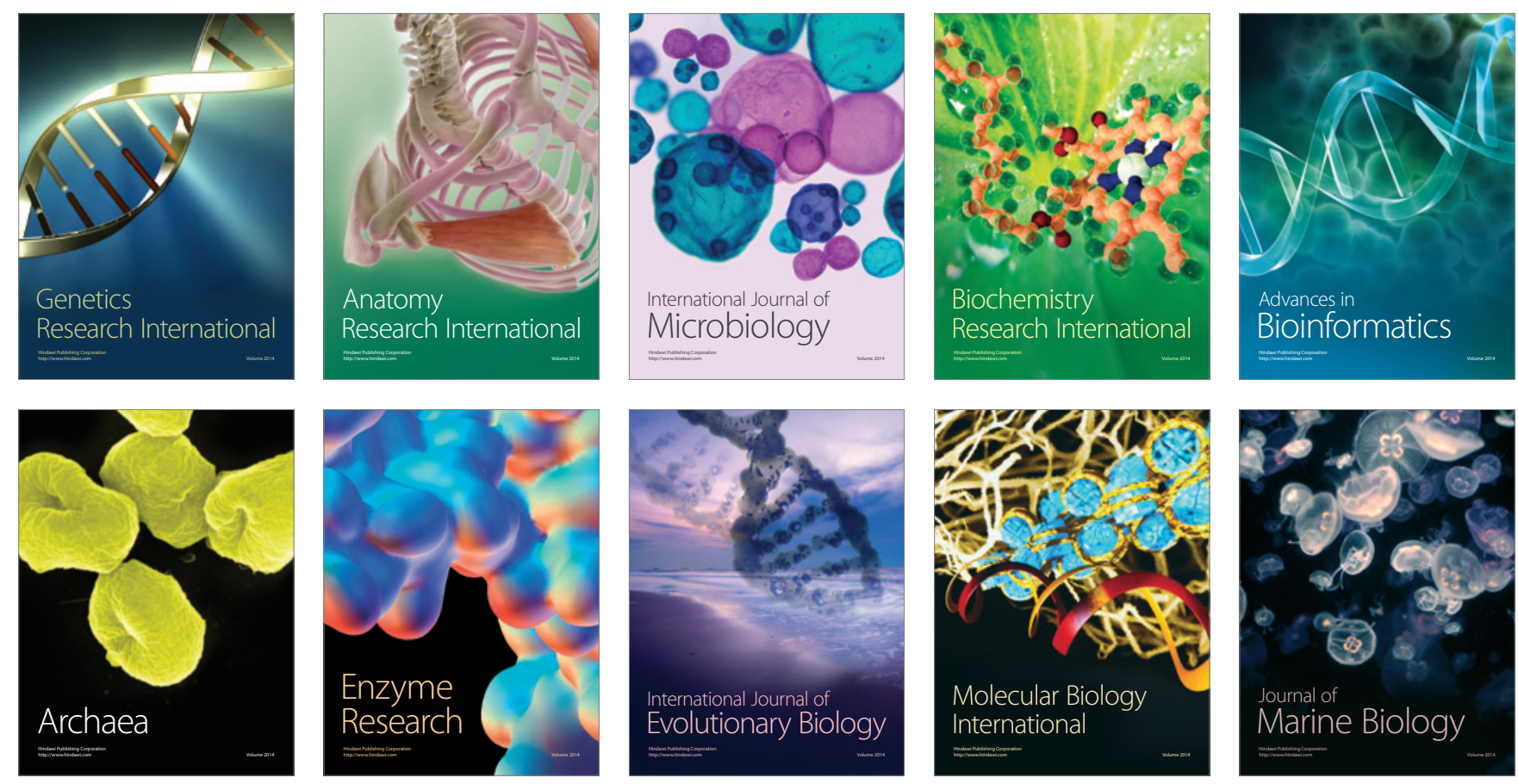